\title{
Safety of Injectable HPßCD-Diclofenac in Older Patients with Acute Moderate-to-Severe Postoperative Pain: A Pooled Analysis of Three Phase III Trials
}

\author{
Jacques E. Chelly ${ }^{1}$ Peter G. Lacouture ${ }^{2,3} \cdot$ Christian Russel D. Reyes $^{4}$
}

Published online: 1 March 2018

(C) The Author(s) 2018. This article is an open access publication

\begin{abstract}
Background Hydroxypropyl- $\beta$-cyclodextrin-diclofenac (HPßCD-diclofenac) is an NSAID used to treat acute moderate-to-severe postoperative pain. This post hoc analysis investigated the safety of HPßCD-diclofenac in patients aged $\geq 65$ years.

Methods Data from three phase III trials of HP $\beta C D$-diclofenac in adult patients with acute moderate-to-severe postoperative pain were pooled (NCT00448110, NCT00507026, and NCT00726388). Patients who received one or more dose of HP $\beta C D$-diclofenac or placebo were included and stratified according to age: $<65,65-74$, or $\geq 75$ years. Numerical and categorical variables were compared across the groups using ANOVA and CochranMantel-Haenszel tests, respectively. Cochran-MantelHaenszel relative risks compared with placebo were calculated, adjusted by study.

Results Overall, 1289 patients were included: 878, 282, and 129 in the $<65,65-74$, and $\geq 75$-years groups, respectively. Overall incidence of treatment-emergent adverse events (TEAEs) was similar in the three groups $(p=0.4360)$. Incidences of postoperative anemia $(p<0.0001)$, constipation $(p=0.0017)$, and hypotension $(p=0.0003)$ increased
\end{abstract}

Jacques E. Chelly

ChelJE@anes.upmc.edu

1 Division of Interventional Perioperative Pain, Department of Anesthesiology, University of Pittsburgh and University of Pittsburgh Medical Center, Aiken Medical Building, 532 S Aiken Avenue, Suite 407, Pittsburgh, PA 15232, USA

2 Magidom Discovery, LLC, St. Augustine, FL 32080, USA

3 Brown University School of Medicine, Providence, RI 02912, USA

4 Hospira, Inc., a Pfizer Company, Lake Forest, IL 60045, USA significantly across the age groups, whereas headache $(p=0.0008)$ and flatulence $(p=0.0118)$ decreased significantly. Relative risks for all System Organ Class categories and preferred terms investigated were similar among the groups and similar to placebo.

Conclusions Overall incidence of TEAEs in patients aged $65-74$ or $\geq 75$ years was similar to patients aged $<65$ years. The groups displayed similar relative risks for the most frequent TEAEs, which were all similar to placebo. The TEAE profiles of the groups showed differences, all of which may be anticipated due to age-related differences in susceptibility and the types of surgery most commonly performed in each group.

Clinicaltrials.gov identifiers NCT00448110, NCT005070 26, and NCT00726388.

\section{Key Points}

Overall incidence of treatment-emergent adverse events (TEAEs) was similar in postoperative patients treated with HP $\beta C D$-diclofenac and aged $<65$, $65-74$, or $\geq 75$ years.

Relative risks for all the MedDRA System Organ Class categories and preferred terms investigated were similar among the three age groups and similar to placebo.

The observed differences in the TEAE profiles of the three age groups may be anticipated due to age-related differences in susceptibility and the types of surgery most commonly performed. 


\section{Introduction}

Hydroxypropyl- $\beta$-cyclodextrin-diclofenac (HP $\beta C D$-diclofenac) is an injectable formulation of the non-steroidal anti-inflammatory drug (NSAID) diclofenac, a non-selective cyclooxygenase inhibitor with analgesic, anti-inflammatory, and anti-pyretic effects that was first introduced in Europe more than 30 years ago and subsequently in the US in 1988 [1, 2]. Solubilization of diclofenac with HP $\beta C D$ allows administration as a low-volume intravenous bolus that leads to rapid analgesia [3, 4]. These properties are beneficial when treating patients with acute postoperative pain and several blinded, placebo-controlled phase III trials have demonstrated that intravenous HP $\beta C D$-diclofenac is well tolerated and efficacious when used in this setting, either alone or in combination with opioid analgesics [4-6].

Safety considerations relating to the use of NSAIDs include the potential for adverse gastrointestinal, cardiovascular, bleeding, and renal events, which can limit the suitability of this class in at-risk groups such as older patients and those with pre-existing renal and/or hepatic insufficiency [7-9]. Three previous pooled analyses of safety data from two phase III, parallel-group trials comparing HP $\beta C D$-diclofenac with placebo and ketorolac, another injectable NSAID, in patients with acute moderate-to-severe postoperative pain did not show a higher relative risk for bleeding [10], renal [11], or cardiovascular adverse events (AEs) [12] among patients receiving HP $\beta C D$-diclofenac or ketorolac compared with placebo. However, surgical procedures in older patients at increased risk of the AEs typically associated with the use of NSAIDs are becoming increasingly common and this has led to a commensurate increase in the use of postoperative analgesia in this population. This trend is unlikely to change and therefore it is important to more fully characterize the safety profile of specific analgesics in older postoperative patients in order to inform best practice, especially when considering the greater likelihood of comorbidities, co-medications, physical and/or cognitive impairments, and additional risk factors.

Given the increasing importance of characterizing the safety of postoperative analgesia in older patients, the aim of the current analysis was to pool data from three pivotal phase III trials and investigate the safety of HP $\beta C D$-diclofenac when treating acute moderate-to-severe postoperative pain in patients aged $\geq 65$ years.

\section{Methods}

\subsection{Patients}

Data from three phase III trials of HP $\beta C D$-diclofenac were pooled (ClinicalTrials.gov identifiers: NCT00448110,
NCT00507026, and NCT00726388). The protocols for all three trials adhered to the International Ethical Guidelines for Biomedical Research Involving Human Subjects, the International Conference on Harmonisation Good Clinical Practice guidelines, and the Helsinki Declaration. Each of the three trials was approved by the appropriate institutional review board and all patients provided written informed consent.

NCT00448110 was a randomized, placebo- and activecontrolled trial that included a total of 331 patients aged 18-65 years who experienced moderate-to-severe postoperative pain within $6 \mathrm{~h}$ after abdominal or pelvic surgery, and who were randomized 1:1:1:1 to HP $\beta C D$-diclofenac $18.75 \mathrm{mg}$, HPßCD-diclofenac $37.5 \mathrm{mg}$, ketorolac tromethamine $30 \mathrm{mg}$, or placebo [4]. The first dose of study drug was administered within the first $6 \mathrm{~h}$ after surgery and then every $6 \mathrm{~h}$ until patient discharge or discontinuation/ withdrawal from the trial. The median number of doses received across the treatment groups was 8 (range 1-13). Overall, $14.8 \%$ of patients received study drug for 1 day, $80.6 \%$ for 2 days, and $4.5 \%$ for 3 days.

NCT00507026 was a randomized, placebo- and activecontrolled trial that included a total of 277 patients aged 18-85 years who experienced moderate-to-severe postoperative pain within $6 \mathrm{~h}$ after elective orthopedic surgery, and who were randomized 2:1:1 to HP $\beta C D$-diclofenac, ketorolac tromethamine, or placebo [5]. Randomized patients were stratified according to anticipated length of stay ( $\leq 24$ versus $>24 \mathrm{~h}$ ), as well as by risk, with dosages of HP $\beta C D$-diclofenac in patients categorized as either 'non-high risk', 'high risk', or 'high weight' ( $\geq 95 \mathrm{~kg}$ and without other risk factors) being 37.5, 18.75, and $50 \mathrm{mg}$, respectively, and respective ketorolac dosages in the same three groups being 30, 15, and $30 \mathrm{mg}$, respectively. Patients categorized as high risk were those $<50 \mathrm{~kg}$ in weight, $\geq 65$ years of age, undergoing medical ulcer therapy, with renal or hepatic insufficiency, or with a history of gastrointestinal bleeding or perforation. The first dose of study drug was administered within the first $6 \mathrm{~h}$ after surgery and then every $6 \mathrm{~h}$ until patient discharge. Overall, $61 \%$ of patients received 1-8 doses of study drug, $30 \%$ received 9-12 doses, and 9\% received $>13$ doses; all patients $(100 \%)$ received study drug for $\leq 5$ days.

NCT00726388 was an open-label, multiple-dose safety study that included a total of 971 patients aged 18-85 years who experienced acute moderate-to-severe postoperative pain following abdominal, orthopedic, abdominal/pelvic, or any other surgery that would qualify for $\geq 2$ days of scheduled, parenterally administered NSAIDs [6]. Patients received multiple doses of $\mathrm{HP} \beta C D$-diclofenac $37.5 \mathrm{mg}$ (for patients weighing $<95 \mathrm{~kg}$, or weighing $\geq 95 \mathrm{~kg}$ and with more than one NSAID-related risk factor) or $50 \mathrm{mg}$ (patients weighing $\geq 95 \mathrm{~kg}$ and with one or no NSAID-related 
risk factor) and administration was initiated in the immediate postoperative period as soon as the patient was stable following surgery and according to the study site's usual practice, and then every $6 \mathrm{~h}$ ( \pm 15 minutes) until the patient was completely transitioned to oral analgesics, discharged, discontinued, or had received treatment for 5 days. The median number of doses received across treatment groups was 2 (range 1-5). Overall, $4.2 \%$ of patients received study drug for 1 day, $62.5 \%$ for 2 days, $22.7 \%$ for 3 days, and $10.6 \%$ for $4-5$ days.

\subsection{Patient Groups and Safety Outcomes}

Patients were stratified into three age groups: $<65,65-74$, and $\geq 75$ years due to the availability of data from a meaningful number of patients $>75$ years of age and as an acknowledgment that many patients aged 65-74 years have a standard of health that is appreciably different from that of the majority of patients $>75$ years. General safety was assessed by physical examinations, laboratory tests, vital signs tests, and 12-lead ECG. Treatment-emergent AEs (TEAEs) were defined as those AEs that first occurred or worsened in severity during the course of the study, regardless of their relationship to study drug, and were recorded from baseline or screening through the follow-up periods of 30 days [4] or 30-37 days [5, 6], with TEAEs occurring at or after the first dose of study drug included in the analysis. All TEAEs were assessed by the study-site investigators and coded in accordance with the preferred terms and System Organ Class (SOC) categories defined by the Medical Dictionary for Regulatory Activities (MedDRA) version 12.0.

\subsection{Statistical Analysis}

The analysis included all patients who received at least one dose of HP $\beta C D$-diclofenac or placebo as part of one of the three clinical trials described in Sect. 2.1 (patients randomized to a ketorolac tromethamine arm were not included). The baseline characteristics and the incidences of TEAEs in patients receiving HP $\beta C D$-diclofenac were presented using descriptive statistics. Comparisons of demographic characteristics and incidences of TEAEs across the three age groups were performed using ANOVA for numerical variables and Cochran-Mantel-Haenszel tests for categorical variables; $p$ values $<0.05$ were considered significant. The Cochran-Mantel-Haenszel test is a test of association that takes into account stratification or sources of the data. For the current analysis, the three studies were considered as strata for the Cochran-MantelHaenszel test so that information was not lost when analyzing combined data. Cochran-Mantel-Haenszel relative risks (and 95\% confidence intervals) were calculated for each of the three age groups by comparing incidences of TEAEs in patients receiving HP $\beta C D$-diclofenac with those in patients receiving placebo, adjusted by study. Relative risks were calculated for both the overall SOC categories and any preferred terms whose incidence differed significantly between the three age groups.

\section{Results}

\subsection{Patient Characteristics}

A total of 1289 patients were included in the analysis: 878 in the $<65$-years group, 282 in the 65-74-years group, and 129 in the $\geq 75$-years group. The three age groups differed significantly with regard to mean body weight, gender, racial composition, prevalence of renal impairment, and most frequent type of procedure (Table 1). Mean body weight in the $>75$-years group was approximately $10 \mathrm{~kg}$ lower than in the other two groups. There was a majority of women in all three age groups, with the $<65$-years group having the highest proportion $(69.1 \%)$. The proportion of white patients increased across the three age groups, as did the prevalence of mild renal impairment. The majority of procedures performed in the two older age groups were orthopedic, whereas procedures performed in the $<65$ years group were divided approximately equally between orthopedic and abdominal/pelvic. The mean duration of each procedure was similar across the three age groups $(p=0.3557)$.

Baseline laboratory test results showed that albumin and overall protein levels were lower with increasing age, whereas blood urea nitrogen and creatinine were higher with increasing age $(p<0.0001$ for all; Table 2). Alanine aminotransferase levels were lower with increasing age $(p=0.0006)$, as were levels of alkaline phosphatase ( $p=0.0248$ ), but other markers of liver function were not significantly different. Hematocrit, hemoglobin, erythrocytes, and platelets were lower with increasing age $(p<0.0001$ for all).

\subsection{Safety of HPßCD-Diclofenac}

The proportion of patients who experienced a TEAE was similar in the three age groups ( $p=0.4360$; Table 3$)$. Overall, TEAEs within the SOC category of 'Gastrointestinal disorders' were the most common (49.4-50.4\% of subjects across the three age groups), and this was driven predominantly by cases of nausea and constipation. TEAEs within the SOC categories of 'Injury, poisoning, and procedural complications' (18.3-34.1\% of subjects across the three age groups, driven predominantly by cases of postoperative anemia) and 'General disorders and administration 
Table 1 Baseline demographics and clinical characteristics of patients receiving postoperative HP $\beta C D$-diclofenac

\begin{tabular}{|c|c|c|c|c|}
\hline \multirow[t]{2}{*}{ Variable } & \multicolumn{3}{|l|}{ Age group (years) } & \multirow[t]{2}{*}{$p$ value $^{\mathrm{a}}$} \\
\hline & $<65(N=878)$ & $65-74(N=282)$ & $\geq 75(N=129)$ & \\
\hline Mean (SD) age, years & $49.0(10.8)$ & $69.1(3.0)$ & $78.5(2.8)$ & $<0.0001$ \\
\hline Mean (SD) weight, kg & $89.4(21.8)$ & $88.9(18.2)$ & $78.0(17.4)$ & $<0.0001$ \\
\hline Female gender, $n(\%)$ & $607(69.1)$ & $161(57.1)$ & $82(63.6)$ & 0.0009 \\
\hline Race, $n(\%)$ & & & & $<0.0001$ \\
\hline Asian & $7(0.8)$ & $4(1.4)$ & $1(0.8)$ & \\
\hline Black & 109 (12.4) & $12(4.3)$ & $5(3.9)$ & \\
\hline White & $724(82.5)$ & $261(92.6)$ & $122(94.6)$ & \\
\hline Other & $38(4.3)$ & $5(1.8)$ & $1(0.8)$ & \\
\hline Renal impairment ${ }^{\mathrm{b}}, n(\%)$ & & & & $<0.0001$ \\
\hline Not impaired & $852(97.0)$ & $252(89.4)$ & $112(86.8)$ & \\
\hline Mild & $19(2.2)$ & $29(10.3)$ & $16(12.4)$ & \\
\hline Moderate & $3(0.3)$ & $1(0.4)$ & $0(0.0)$ & \\
\hline Missing & $4(0.5)$ & $0(0.0)$ & $1(0.8)$ & \\
\hline Procedure type, $n(\%)$ & & & & $<0.0001$ \\
\hline Abdominal/pelvic & $418(47.6)$ & $38(13.5)$ & $10(7.8)$ & \\
\hline Orthopedic & $458(52.2)$ & $244(86.5)$ & $119(92.2)$ & \\
\hline Other & $2(0.2)$ & $0(0.0)$ & $0(0.0)$ & \\
\hline Procedure duration, $\mathrm{h}$ & & & & 0.3557 \\
\hline Mean (SD) & $1.53(1.01)$ & $1.59(0.79)$ & $1.45(0.61)$ & \\
\hline Median (range) & $1.33(0.17-12.5)$ & $1.34(0.33-5.35)$ & $1.32(0.17-3.63)$ & \\
\hline
\end{tabular}

$S D$ standard deviation

${ }^{a}$ Comparison of the three age groups was via ANOVA for numerical variables and Cochran-MantelHaenszel test for categorical variables

${ }^{\mathrm{b}}$ Defined by creatinine level at screening: not impaired ( $\leq 1.0 \times$ upper limit of the normal range [ULN]); mild $(>1.0$ to $\leq 1.5 \times \mathrm{ULN})$; or moderate $(>1.5 \times \mathrm{ULN})$

Table 2 Baseline laboratory test values of patients receiving postoperative HP $\beta C D$-diclofenac

\begin{tabular}{|c|c|c|c|c|}
\hline \multirow[t]{2}{*}{ Laboratory parameter ${ }^{\mathrm{a}}$} & \multicolumn{3}{|l|}{ Age group (years) } & \multirow[t]{2}{*}{$p$ value $^{\mathrm{b}}$} \\
\hline & $<65$ & $65-74$ & $\geq 75$ & \\
\hline Albumin, g/L & $38.5(6.1)[855]$ & $36.1(5.4)[277]$ & $35.1(5.1)[125]$ & $<0.0001$ \\
\hline Protein, g/L & $64.1(8.9)[855]$ & $60.0(8.4)[277]$ & $58.6(8.2)[125]$ & $<0.0001$ \\
\hline Blood urea nitrogen, $\mathrm{mmol} / \mathrm{L}$ & $5.0(1.7)[855]$ & $6.2(2.1)[277]$ & $6.7(2.3)[125]$ & $<0.0001$ \\
\hline Creatinine, $\mu \mathrm{mol} / \mathrm{L}$ & $76.9(16.0)[855]$ & $83.6(20.4)[277]$ & 84.9 (21.8) [125] & $<0.0001$ \\
\hline Alanine aminotransferase, IU/L & $24.0(26.5)[855]$ & 20.5 (19.2) [277] & $15.9(8.3)[125]$ & 0.0006 \\
\hline Aspartate aminotransferase, IU/L & $24.8(33.8)[855]$ & $25.4(31.0)[277]$ & $22.4(14.3)[125]$ & 0.6711 \\
\hline Gamma glutamyltransferase, IU/L & $37.9(64.0)[582]$ & 31.5 (41.0) [247] & $27.3(25.7)[113]$ & 0.0934 \\
\hline Alkaline phosphatase, IU/L & 72.9 (23.7) [855] & $69.5(23.3)[277]$ & $68.1(23.2)[125]$ & 0.0248 \\
\hline Total bilirubin, $\mu \mathrm{mol} / \mathrm{L}$ & $8.1(5.3)[855]$ & $8.5(5.0)[277]$ & $8.6(4.7)[125]$ & 0.4346 \\
\hline Hematocrit & $0.38(0.05)[835]$ & $0.38(0.05)[270]$ & $0.36(0.04)[123]$ & $<0.0001$ \\
\hline Hemoglobin, g/L & $128.0(17.2)[847]$ & $124.7(16.4)[274]$ & $119.4(15.2)[124]$ & $<0.0001$ \\
\hline Erythrocytes, $\times 10^{12} / \mathrm{L}$ & $4.3(0.5)[847]$ & $4.1(0.5)[274]$ & $3.9(0.5)[124]$ & $<0.0001$ \\
\hline Platelets, $\times 10^{9} / \mathrm{L}$ & $292.5(80.0)$ [833] & $263.6(80.3)[269]$ & $256.5(71.0)[122]$ & $<0.0001$ \\
\hline Leukocytes, $\times 10^{9} / \mathrm{L}$ & $8.9(3.9)[835]$ & $8.5(3.3)[270]$ & $8.2(3.0)[123]$ & 0.0654 \\
\hline
\end{tabular}

${ }^{a}$ All values are mean (standard deviation) $[n]$

${ }^{\mathrm{b}}$ Comparison of the three age groups was via ANOVA 
Table 3 Incidence of treatment-emergent adverse events (TEAEs) in patients receiving postoperative HP $\beta C D$-diclofenac, according to MedDRA System Organ Class (SOC)

\begin{tabular}{|c|c|c|c|c|}
\hline \multirow[t]{2}{*}{ Variable } & \multicolumn{3}{|c|}{ Age group (years) } & \multirow[t]{2}{*}{$p$ value $^{\mathrm{a}}$} \\
\hline & $<65(N=878)$ & $65-74(N=282)$ & $\geq 75(N=129)$ & \\
\hline TEAEs, $n$ & 2274 & 855 & 497 & - \\
\hline Patients experiencing $\geq 1$ TEAE, $n(\%)$ & $712(81.1)$ & $236(83.7)$ & $109(84.5)$ & 0.4360 \\
\hline \multicolumn{5}{|l|}{ Most frequent TEAEs ${ }^{\mathrm{b}}, n(\%)^{\mathrm{c}}$} \\
\hline Blood and lymphatic system disorders & $27(3.1)$ & $15(5.3)$ & $9(7.0)$ & 0.0390 \\
\hline Cardiac disorders & $37(4.2)$ & $17(6.0)$ & $11(8.5)$ & 0.1691 \\
\hline Gastrointestinal disorders & $434(49.4)$ & $140(49.6)$ & $65(50.4)$ & 0.9576 \\
\hline Nausea & $283(32.2)$ & $93(33.0)$ & $42(32.6)$ & 0.8988 \\
\hline Constipation & $126(14.4)$ & $53(18.8)$ & $33(25.6)$ & 0.0017 \\
\hline Vomiting & $62(7.1)$ & $24(8.5)$ & $10(7.8)$ & 0.7907 \\
\hline Flatulence & $68(7.7)$ & $7(2.5)$ & $0(0.0)$ & 0.0118 \\
\hline General disorders and administration site conditions & $185(21.1)$ & $66(23.4)$ & $26(20.2)$ & 0.2815 \\
\hline Infusion site pain & $65(7.4)$ & $20(7.1)$ & $3(2.3)$ & 0.1315 \\
\hline Pyrexia & $44(5.0)$ & $17(6.0)$ & $9(7.0)$ & 0.7018 \\
\hline Edema peripheral & $24(2.7)$ & $16(5.7)$ & $6(4.7)$ & 0.1403 \\
\hline Infections and infestations & $78(8.9)$ & $30(10.6)$ & $14(10.9)$ & 0.9429 \\
\hline Injury, poisoning, and procedural complications & $161(18.3)$ & $85(30.1)$ & $44(34.1)$ & 0.0043 \\
\hline Anemia postoperative & $104(11.8)$ & $64(22.7)$ & $41(31.8)$ & $<0.0001$ \\
\hline Investigations & $127(14.5)$ & $43(15.2)$ & $21(16.3)$ & 0.8913 \\
\hline Blood creatine phosphokinase increased & $76(8.7)$ & $15(5.3)$ & $7(5.4)$ & 0.1604 \\
\hline Metabolism and nutrition disorders & $52(5.9)$ & $15(5.3)$ & $16(12.4)$ & 0.0448 \\
\hline Musculoskeletal and connective tissue disorders & $63(7.2)$ & $22(7.8)$ & $16(12.4)$ & 0.1588 \\
\hline Nervous system disorders & $140(15.9)$ & $28(9.9)$ & 15 (11.6) & 0.0275 \\
\hline Dizziness & $45(5.1)$ & $11(3.9)$ & $10(7.8)$ & 0.2492 \\
\hline Headache & $71(8.1)$ & $9(3.2)$ & $1(0.8)$ & 0.0008 \\
\hline Psychiatric disorders & $107(12.2)$ & $48(17.0)$ & $30(23.3)$ & 0.0071 \\
\hline Insomnia & $88(10.0)$ & $39(13.8)$ & $20(15.5)$ & 0.1539 \\
\hline Renal and urinary disorders & $31(3.5)$ & $15(5.3)$ & $12(9.3)$ & 0.0081 \\
\hline Respiratory, thoracic, and mediastinal disorders & $70(8.0)$ & $22(7.8)$ & $21(16.3)$ & 0.0166 \\
\hline Skin and subcutaneous tissue disorders & $131(14.9)$ & $55(19.5)$ & $21(16.3)$ & 0.5326 \\
\hline Pruritus & $91(10.4)$ & $32(11.3)$ & $12(9.3)$ & 0.6811 \\
\hline Vascular disorders & $78(8.9)$ & $30(10.6)$ & $23(17.8)$ & 0.0057 \\
\hline Hypotension & $36(4.1)$ & $14(5.0)$ & $17(13.2)$ & 0.0003 \\
\hline
\end{tabular}

MedDRA Medical Dictionary for Regulatory Activities version 12.0

${ }^{a}$ Comparison of the three age groups was via Cochran-Mantel-Haenszel test

${ }^{\mathrm{b}} \mathrm{SOC}$ categories within which the incidence of TEAEs was $>5 \%$ for any one of the three age groups. All preferred terms with an incidence $>5 \%$ in any one of the three age groups are shown under each SOC category

${ }^{c}$ Percentages are based on the number of subjects. Subjects were counted once within each SOC category or for each preferred term and may have experienced more than one TEAE

site conditions' (20.2-23.4\% of subjects, driven predominantly by cases of injection site pain and pyrexia) were the next most common. There was a significant difference in the incidence of TEAEs between the three age groups for the following SOC categories: 'Blood and lymphatic system disorders' (driven mainly by an increasing frequency of anemia: $1.5,3.2$, and $3.9 \%$ in the $<65,65-74$, and $\geq 75$ years age groups, respectively; $p=0.0215$ ); 'Injury, poisoning, and procedural complications' (driven mainly by an increasing frequency of postoperative anemia; $p<0.0001$ ); 'Metabolism and nutrition disorders' (driven mainly by a higher frequency of hyponatremia in the oldest group: 0.8 , 
0.4 , and $3.9 \%$ in the $<65,65-74$, and $\geq 75$-years age groups, respectively; $p=0.0089$ ); 'Nervous system disorders' (driven mainly by a decreasing frequency of headache; $p=0.0008$ ); 'Psychiatric disorders'; 'Renal and urinary disorders' (driven mainly by an increasing frequency of acute renal failure: $0.1,0.4$, and $3.9 \%$ in the $<65,65-74$, and $\geq 75$-years age groups, respectively; $p<0.0001$ ); 'Respiratory, thoracic, and mediastinal disorders' (driven mainly by a higher frequency of cough in the oldest group: 1.0, 0.7, and $4.7 \%$ in the $<65,65-74$, and $\geq 75$-years age groups, respectively; $p<0.0028$; and 'Vascular disorders' (driven mainly by an increasing frequency of hypotension; $p=0.0003$ ). There was also a significant difference between the age groups with regard to the preferred terms of constipation $(p=0.0017)$, which increased in incidence with increasing age, and flatulence $(p=0.0118)$, which decreased in incidence with increasing age. The incidence of TEAEs related to postoperative bleeding was low $(<1 \%$ for each specific TEAE in the patients receiving HP $\beta C D$-diclofenac for all three age groups), with no significant difference between patients receiving HP $\beta C D$-diclofenac and those receiving placebo.

Stratification of TEAE data according to severity showed that similar proportions of patients in the $<65$, $65-74$, and $\geq 75$-years age groups experienced mild (32.5, 33.0 , and $27.1 \%$, respectively), moderate (43.4, 45.7, and $51.9 \%$, respectively), and severe TEAEs (5.2, 5.0, and $5.4 \%$, respectively). Statistical comparisons after stratification according to the dose of HP $\beta C D$-diclofenac received were not possible due to the small number of patients in some of the groups (respective patient numbers in the $<65,65-74$, and $\geq 75$ years age groups were 92,29 , and 12 for $18.75 \mathrm{mg}$; 516, 171, and 99 for $37.5 \mathrm{mg}$; and 270,82 , and 18 for $50.5 \mathrm{mg}$ ), but the overall incidence of TEAEs was similar in the $<65,65-74$, and $\geq 75$-years age groups at doses of $18.75 \mathrm{mg}(83.7,79.3$, and $75.0 \%$, respectively), $37.5 \mathrm{mg}(81.8,84.2$, and $86.9 \%$, respectively), and $50.5 \mathrm{mg}(78.9,84.1$, and $77.8 \%$, respectively). Statistical comparisons after stratification according to the type of procedure were not possible due to the small number of patients in the two older groups (patient numbers in the $<65,65-74$, and $\geq 75$-years age groups were 418,38 , and 10 , respectively, for abdominal/pelvic procedures, and 458, 244, and 119, respectively, for orthopedic procedures), but the overall incidence of TEAEs was similar in the $<65,65-74$, and $\geq 75$-years age groups for abdominal/pelvic procedures $(83.7,76.3$, and $80.0 \%$, respectively) and orthopedic procedures $(78.6,84.8$, and $84.9 \%$, respectively).

For all three age groups, patients who received HP $\beta C D-$ diclofenac displayed a relative risk of experiencing a TEAE of any type, or a TEAE of a specific SOC category or preferred term whose incidence differed significantly
Fig. 1 Cochran-Mantel-Haenszel relative risks of treatment-emergent adverse events (TEAEs) in System Organ Class (SOC) categories (a) and of specific preferred terms (b) after postoperative treatment with HP $\beta C D$-diclofenac compared with placebo. Presented SOC categories and preferred terms are those identified as having a significantly different incidence across the three age groups (see Table 3). Data for some SOC categories or preferred terms are missing due to a lack of incidence in the placebo group preventing the calculation of relative risk

between the three age groups as indicated in Table 3, that was no greater than that of patients who received placebo (Fig. 1). Furthermore, the 95\% confidence intervals of the relative risks calculated for each of the three age groups overlapped with one another for every SOC category or preferred term investigated. The time of onset for TEAEs was similar among the three age groups, with the incidence peaking at Day 2 when all TEAEs combined were considered (Fig. 2). The times of onset for the specific preferred terms identified as having a significantly different incidence across the age groups were similar, except for constipation, which peaked at Day 2 in the $<65$-years group compared with Days 3 or 4 in the two older groups, and hypotension, which peaked at Day 1 in the $>75$-years group compared with Day 2 in the two younger groups.

\section{Discussion}

The widespread increase in life expectancy achieved in the last 50 years or so has led to an increasing number of older patients undergoing surgery. There is greater concern regarding drug safety in this population due to the well established decline in many physiological functions associated with aging [13-16]. This is especially true with regard to the use of anti-inflammatory drugs that can negatively affect renal and/or gastrointestinal function [17-20]. Understanding the risks associated with the use of specific analgesics in older patients, especially in the acute postoperative setting, is therefore critical for optimizing clinical outcomes and minimizing TEAEs.

Previous statistical analyses have stratified data according to age $\geq 65$ years in order to represent 'older patients'. Given the increasing life expectancy and the availability of data from a meaningful number of patients $>75$ years of age, this analysis stratified patients into groups of $<65,65-74$, and $\geq 75$ years as an acknowledgment that many patients aged $65-74$ years have a standard of health that is appreciably different from that of the majority of patients $>75$ years. Our analysis of pooled data from three pivotal trials of HP $\beta C D$-diclofenac provides original data for patients aged $65-74$ years or $\geq 75$ years and confirms the safety of postoperative HP $\beta C D$ - 


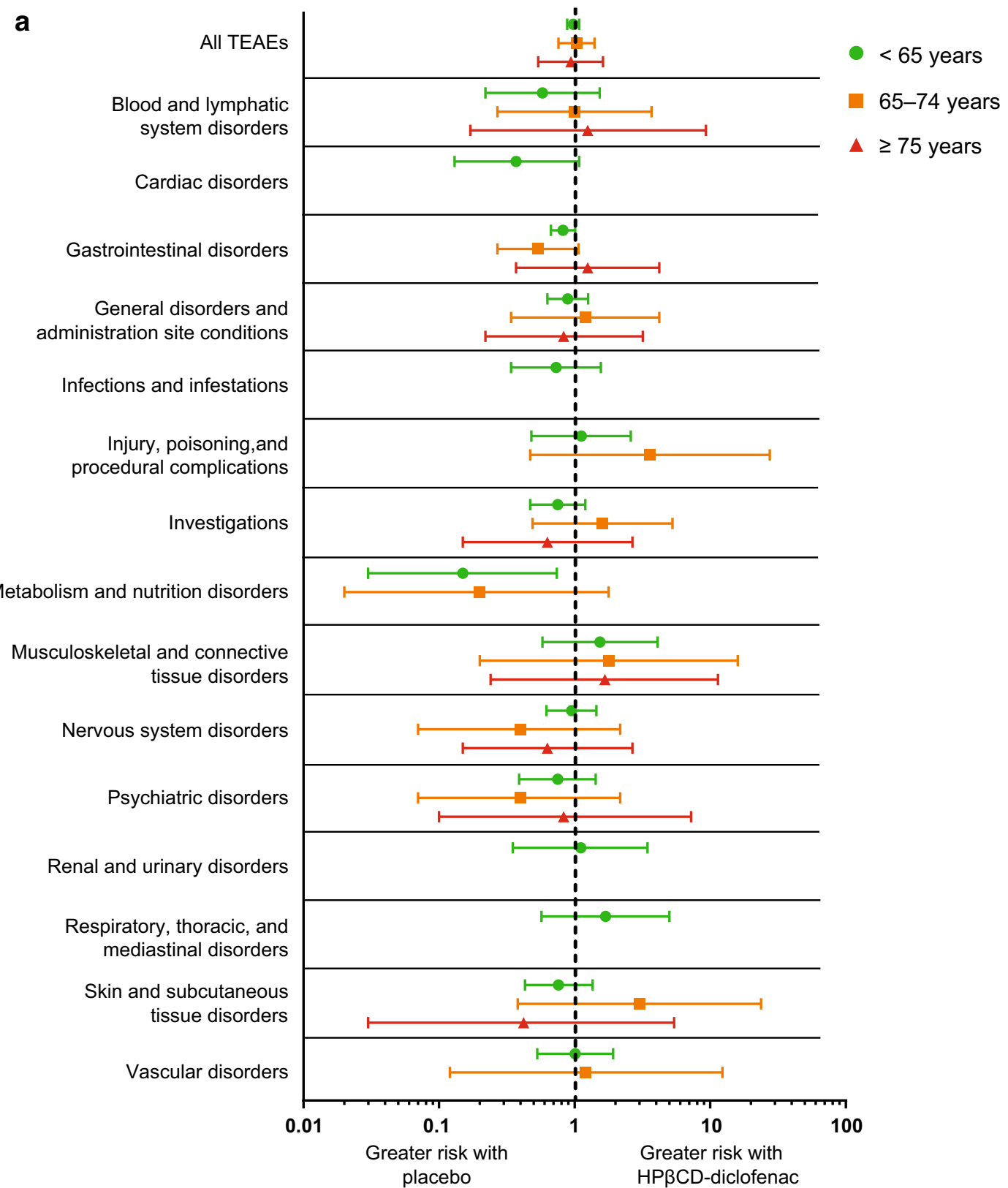

b

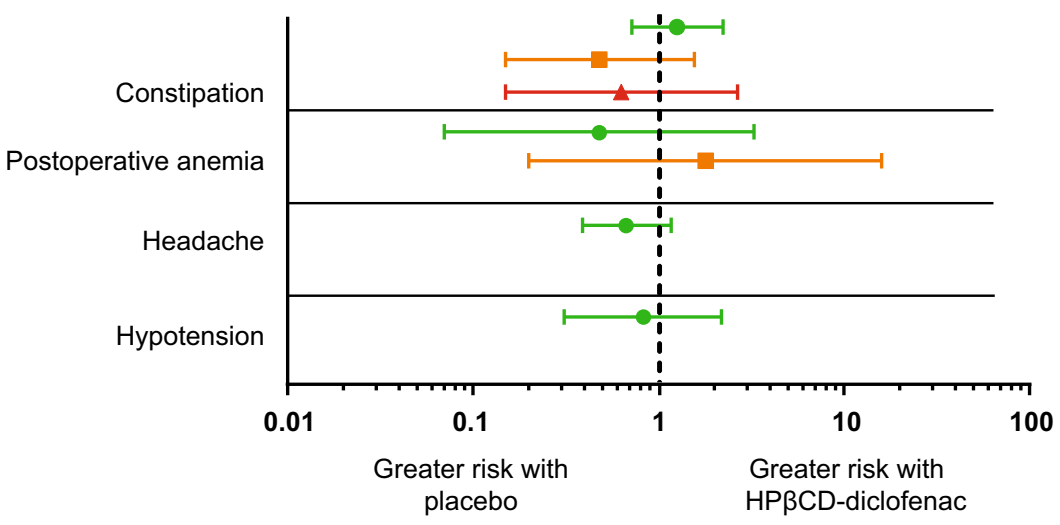



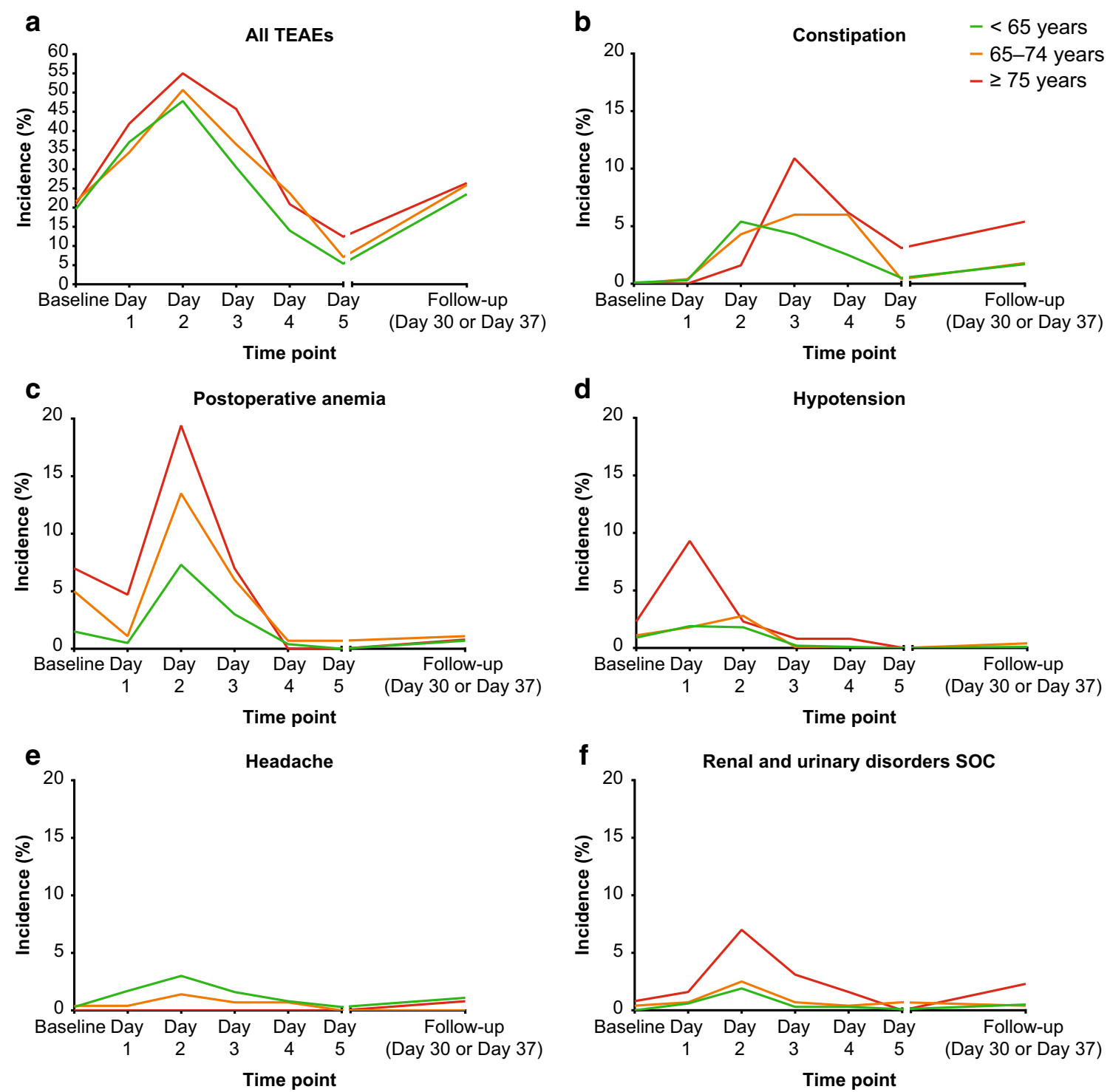

Fig. 2 Time course for onset of treatment-emergent adverse events (TEAEs) in patients receiving postoperative HP $\beta C D$-diclofenac for acute moderate-to-severe pain. SOC System Organ Class

diclofenac by demonstrating that the overall incidences of TEAEs in these two groups are similar to the incidence observed in patients $<65$ years of age. Furthermore, the relative risks of patients treated with $\mathrm{HP} \beta C D$-diclofenac experiencing TEAEs were similar among the three age groups for every relevant SOC category or preferred term for which they could be calculated, and were also similar to the relative risks associated with placebo.

Previous analyses of safety data from two double-blind, parallel-group, phase III trials comparing the use of HP $\beta C D$ diclofenac with placebo and ketorolac in adult patients with acute moderate-to-severe postoperative pain showed that the most frequent AEs reported in the active treatment arms were nausea, vomiting, flatulence, injection site pain/irritation, and constipation $[4,5]$. A subsequent open-label, single-arm, phase III trial, which also included patients considered 'at risk' due to being older, anticoagulated, and/or with renal insufficiency, reported that the most common TEAEs in the overall population were nausea, postoperative anemia, constipation, and insomnia [6]. Concomitant use of NSAIDs and anticoagulant drugs has previously been identified as a risk factor for clinically relevant bleeding-related AEs [21, 22], but each of the three trials described above reported similar incidences in patients receiving or not receiving anticoagulant drugs. It should be noted, however, that these three trials involved relatively brief HP $\beta C D$-diclofenac treatment periods and caution should be exercised with the concomitant use of NSAIDs and anticoagulant drugs in the long term.

None of the three pivotal trials mentioned above considered the age of the patients. The current analysis, which 
pooled patient data from all three trials and stratified them according to age, showed that the most frequent TEAEs in each of the age groups receiving HP $\beta C D$-diclofenac were gastrointestinal disorders (mainly nausea and constipation), postoperative anemia, and events relating to intravenous administration (injection site pain and pyrexia). Nausea was the most frequent TEAE reported in all three age groups and showed no age-related difference in incidence (range 32.2-33.0\%). It should be noted that postoperative nausea and vomiting are frequently reported following surgery [23] and the incidences of both were previously shown to be lower in patients treated with HP $\beta C D$-diclofenac or ketorolac compared with placebo (nausea $38.2 \%$ for placebo; 30.2 and $25.3 \%$ for HPßCD-diclofenac 18.75 and $37.5 \mathrm{mg}$, respectively; $26.8 \%$ for ketorolac $30 \mathrm{mg}$; and vomiting: $14.5 \%$ for placebo; 8.1 and $5.7 \%$ for HPßCD-diclofenac 18.75 and $37.5 \mathrm{mg}$, respectively; $8.5 \%$ for ketorolac $30 \mathrm{mg}$ ) [4]. Many of the differences in the incidences of specific TEAEs observed in the three age groups are likely to be heavily influenced by underlying physiologic differences between the groups at baseline, as well as by the different types of surgery that are most common in the different age groups. For example, the increasing incidence of constipation across the three age groups may be anticipated due to the greater prevalence of the condition in older individuals in general [24], while the increasing incidence of anemia and postoperative anemia across the groups is likely due to significant, age-related differences in baseline hematology parameters (e.g., hematocrit, hemoglobin, erythrocytes, and platelets all decreased with age in the cohort analyzed). Likewise, the increasing incidence of renal TEAEs across the age groups may be expected due to the higher prevalence of mild renal impairment in the two older age groups at baseline and because of the greater risk of acute kidney injury in older individuals [25].

The age-stratified data from the current analysis support and expand upon the observations reported in the three previous pooled analyses of bleeding, renal, and cardiovascular AEs in the two double-blind trials of $\mathrm{HP} \beta C D$ diclofenac by also including a large number of patients from the open-label trial, which included large numbers of at-risk patients in an attempt to more accurately reflect real-world practice [10-12]. The current analysis found that the relative risks of bleeding AEs, compared with placebo, in patients receiving HP $\beta C D$-diclofenac and aged $65-74$ or $\geq 75$ years were similar to the risk in those aged $<65$ years, and the risks in all three age groups were not significantly different from placebo. The incidence of postoperative anemia increased with increasing age but, as stated above, this is likely due to baseline differences between the age groups. There were no cases of anemia considered related to HP $\beta C D$-diclofenac treatment reported in the open-label, single-arm trial that included atrisk patients, and which contributed the majority of patients included in the current analysis [6]. Comparison of the relative risks of renal and urinary AEs in the current analysis was confounded by a lack of incidence of these events in the placebo group for the two older age groups, but the overall incidence in this SOC category was low and the $<65$-years group showed a relative risk similar to placebo.

A limitation of this post hoc analysis is the pooling of data from clinical trials with different designs, which was necessary in order to achieve sample sizes for the two older age groups that would support meaningful analysis and interpretation. Due to their lower frequency in the general and surgical populations, the $>75$-years group contained fewer patients than the two younger age groups (129 patients compared with 878 in the $<65$-years group and 282 in the 65-74-years group) and therefore the findings presented should be interpreted with an understanding of this limitation. We did not analyze patient data stratified according to the type of procedure that each patient underwent due to the small numbers of patients present in some of the groups following stratification: for example, there were only 38 and 10 patients in the 65-74 and $\geq 75$ years groups, respectively, who underwent abdominal/ pelvic procedures. We cannot rule out that the type of procedure a patient has undergone could influence the risk and frequency of some TEAEs occurring after the administration of postoperative HP $\beta C D$-diclofenac. The three age groups also displayed some significant baseline differences with regard to clinical laboratory parameters and these represent a potential source of bias in the analysis because we chose not to control for these parameters. Likewise, the analysis was not adjusted with regard to the patients' prior medication history and this may represent another source of bias. We chose not to adjust the analysis for baseline differences in clinical laboratory results and prior medication history because these variables reflect the nature of the different age groups investigated.

\section{Conclusions}

The findings from the current analysis demonstrate that the use of HP $\beta C D$-diclofenac for the treatment of acute postoperative pain is as well tolerated by older patients as it is by younger patients, with the overall incidence of TEAEs in patients aged $65-74$ years or $\geq 75$ years being similar to the incidence in those aged $<65$ years. Furthermore, all three age groups treated with HP $\beta C D$-diclofenac displayed similar relative risks for the most common TEAEs, which were also similar for patients treated with placebo. The nature of the TEAEs experienced by the three age groups 
showed differences, such as higher incidences of constipation, postoperative anemia, and hypotension in the older age groups, all of which may be anticipated due to agerelated differences in susceptibility and the types of surgery most commonly performed in the different age groups.

Similar to all intravenous NSAIDs, HP $\beta C D$-diclofenac should be used with caution in older postoperative patients due to advanced age being an independent risk factor for postoperative acute renal failure [26, 27]. Data from the current study reinforces the need for this caution because we found a significantly greater incidence of acute renal failure in those aged $>75$ years $(3.9 \%)$ than was observed in those aged $<65$ years $(0.1 \%)$ or $65-74$ years $(0.4 \%)$. It should also be noted that the large open-label trial that contributed the majority of the patient data included in this pooled analysis reported that patients with mild renal impairment prior to surgery (as determined by serum creatinine levels) displayed a significantly greater incidence of key renal-related TEAEs compared with those without renal impairment [6]. A higher incidence of acute renal failure was also observed in patients undergoing procedures $\geq 2 \mathrm{~h}$ in duration compared with those undergoing

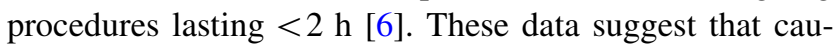
tion regarding potential renal-related TEAEs is warranted when considering the use of postoperative HP $\beta C D$-diclofenac to treat acute moderate-to-severe pain in patients $>75$ years of age, or those with pre-existing renal impairment, or those who had a procedure lasting $\geq 2 \mathrm{~h}$ in duration.

Acknowledgements This study was sponsored by Hospira, Inc., which was acquired by Pfizer in September 2015. Medical writing support was provided by David Wateridge, $\mathrm{PhD}$, of Engage Scientific Solutions and was funded by Pfizer.

Author contributions Jacques E. Chelly and Peter G. Lacouture were responsible for the conception and design of the study, interpretation of the data, and drafting of the manuscript. Christian Russel D. Reyes performed the statistical analysis, interpreted the data, and drafted the manuscript. All authors read and approved the final manuscript.

\section{Compliance with Ethical Standards}

Conflict of interest Jacques E. Chelly reports no conflict of interest. Peter G. Lacouture is a former employee of Hospira. Christian Russel D. Reyes is an employee of Pfizer and holds stock options with Pfizer.

Funding This study was sponsored by Hospira, Inc., which was acquired by Pfizer in September 2015. The three clinical trials included in the analysis were sponsored by Javelin Pharmaceuticals, Inc., which was acquired by Hospira, Inc. in 2010.

Ethical approval and informed consent All three trials included in this analysis adhered to the International Ethical Guidelines for Biomedical Research Involving Human Subjects, the International Conference on Harmonisation Good Clinical Practice guidelines, and the Helsinki Declaration. Each of the three trials was approved by the appropriate institutional review board and all patients provided written informed consent.

Open Access This article is distributed under the terms of the Creative Commons Attribution-NonCommercial 4.0 International License (http://creativecommons.org/licenses/by-nc/4.0/), which permits any noncommercial use, distribution, and reproduction in any medium, provided you give appropriate credit to the original author(s) and the source, provide a link to the Creative Commons license, and indicate if changes were made.

\section{References}

1. Hoy SM. Diclofenac sodium bolus injection (Dyloject(TM)): a review in acute pain management. Drugs. 2016;76(12):1213-20.

2. Altman R, Bosch B, Brune K, Patrignani P, Young C. Advances in NSAID development: evolution of diclofenac products using pharmaceutical technology. Drugs. 2015;75(8):859-77.

3. Loftsson T, Hreinsdóttir D, Másson M. Evaluation of cyclodextrin solubilization of drugs. Int J Pharm. 2005;302(1-2):18-28.

4. Gan TJ, Daniels SE, Singla N, Hamilton DA, Carr DB. A novel injectable formulation of diclofenac compared with intravenous ketorolac or placebo for acute moderate-to-severe pain after abdominal or pelvic surgery: a multicenter, double-blind, randomized, multiple-dose study. Anesth Analg. 2012;115(5): 1212-20.

5. Daniels S, Melson T, Hamilton DA, Lang E, Carr DB. Analgesic efficacy and safety of a novel injectable formulation of diclofenac compared with intravenous ketorolac and placebo after orthopedic surgery: a multicenter, randomized, double-blinded, multipledose trial. Clin J Pain. 2013;29(8):655-63.

6. Chelly JE, Singla SK, Melson TI, Lacouture PG, Paadre S, Carr DB. Safety of a novel parenteral formulation of diclofenac after major orthopedic or abdominal/pelvic surgery in a population including anticoagulated, elderly or renally insufficient patients: an open-label, multiday, repeated dose clinical trial. Pain Med. 2013;14(5):749-61.

7. Souter AJ, Fredman B, White PF. Controversies in the perioperative use of nonsterodial antiinflammatory drugs. Anesth Analg. 1994;79(6):1178-90.

8. Aubrun F, Marmion F. The elderly patient and postoperative pain treatment. Best Pract Res Clin Anaesthesiol. 2007;21(1):109-27.

9. Gurwitz JH. NSAIDs and atrial fibrillation. BMJ. 2011;343:d2495.

10. Gan TJ, Singla N, Daniels SE, et al. Clinical and laboratory hematologic findings in patients receiving repeated-dose injectable $\mathrm{Hp} \beta \mathrm{cd}$-diclofenac for acute postoperative pain: pooled analysis of two randomized controlled phase III clinical trials. J Anesth Clin Res. 2015;6(7):538.

11. Daniels SE, Gan TJ, Hamilton DA, et al. A pooled analysis evaluating renal safety in placebo- and active comparator-controlled phase III trials of multiple-dose injectable HPßCD-diclofenac in subjects with acute postoperative pain. Pain Med. 2016;17(12):2378-88.

12. Gan TJ, Singla N, Daniels SE, et al. Cardiovascular safety of hydroxypropyl- $\beta$-cyclodextrin-diclofenac in the management of acute postsurgical pain: a pooled analysis of 2 randomized, double-blind, placebo- and active comparator-controlled phase III clinical trials. J Clin Anesth. 2016;31:249-58.

13. McLean AJ, Le Couteur DG. Aging biology and geriatric clinical pharmacology. Pharmacol Rev. 2004;56(2):163-84.

14. Hilmer SN, McLachlan AJ, Le Couteur DG. Clinical pharmacology in the geriatric patient. Fundam Clin Pharmacol. 2007;21(3):217-30. 
15. Chester JG, Rudolph JL. Vital signs in older patients: age-related changes. J Am Med Dir Assoc. 2011;12(5):337-43.

16. Alvis BD, Hughes CG. Physiology considerations in geriatric patients. Anesthesiol Clin. 2015;33(3):447-56.

17. Savage R. Cyclo-oxygenase- 2 inhibitors: when should they be used in the elderly? Drugs Aging. 2005;22(3):185-200.

18. Barkin RL, Beckerman M, Blum SL, Clark FM, Koh EK, Wu DS. Should nonsteroidal anti-inflammatory drugs (NSAIDs) be prescribed to the older adult? Drugs Aging. 2010;27(10):775-89.

19. Abdulla A, Adams N, Bone M, et al. Guidance on the management of pain in older people. Age Ageing. 2013;42(Suppl 1):i1-57.

20. McKeown JL. Pain management issues for the geriatric surgical patient. Anesthesiol Clin. 2015;33(3):563-76.

21. Forrest JB, Camu F, Greer IA, et al. Ketorolac, diclofenac, and ketoprofen are equally safe for pain relief after major surgery. $\mathrm{Br}$ J Anaesth. 2002;88(2):227-33.

22. Davidson BL, Verheijen S, Lensing AW, et al. Bleeding risk of patients with acute venous thromboembolism taking nonsteroidal anti-inflammatory drugs or aspirin. JAMA Intern Med. 2014;174(6):947-53.

23. Gan TJ. Risk factors for postoperative nausea and vomiting. Anesth Analg. 2006;102(6):1884-98.

24. Gallegos-Orozco JF, Foxx-Orenstein AE, Sterler SM, Stoa JM. Chronic constipation in the elderly. Am J Gastroenterol. 2012;107(1):18-25.

25. Anderson S, Eldadah B, Halter JB, et al. Acute kidney injury in older adults. J Am Soc Nephrol. 2011;22(1):28-38.

26. Kheterpal S, Tremper KK, Englesbe MJ, et al. Predictors of postoperative acute renal failure after noncardiac surgery in patients with previously normal renal function. Anesthesiology. 2007;107(6):892-902.

27. Kheterpal S, Tremper KK, Heung M, et al. Development and validation of an acute kidney injury risk index for patients undergoing general surgery: results from a national data set. Anesthesiology. 2009;110(3):505-15. 